\title{
Estratégias de defesa contra o sofrimento no trabalho de docentes da pós-graduação stricto sensu
}

\author{
Chancarlyne Vivian ${ }^{\mathrm{I}, 1}$, Letícia de Lima Trindade ${ }^{\mathrm{I}, 2}$, Ricardo Rezer ${ }^{\mathrm{I}, 3}$, \\ Carine Vendruscolo ${ }^{\mathrm{II}, 4}$ e Sinval Adalberto Rodrigues Junior, ${ }^{\mathrm{I}, 5}$ \\ ${ }^{\mathrm{I}}$ Universidade Comunitária da Região de Chapecó (Chapecó, SC, Brasil) \\ II Universidade do Estado de Santa Catarina (Chapecó, SC, Brasil)
}

\begin{abstract}
O estudo objetivou identificar as estratégias de defesa contra o sofrimento no trabalho desenvolvidas por docentes da pós-graduação stricto sensu. Trata-se de pesquisa descritiva, com abordagem qualitativa. Participaram 47 docentes de uma universidade do Sul do Brasil, que responderam a um questionário baseado no Inventário sobre Trabalho e Riscos de Adoecimento, sendo que dois representantes de cada um dos sete programas de pós-graduação stricto sensu da universidade também foram entrevistados. A investigação foi aprovada no Comitê de Ética da instituição e a coleta de dados ocorreu entre outubro de 2018 e março de 2019. Os docentes utilizam, predominantemente, estratégias de defesa individuais, dentre elas a psicoterapia, a religiosidade/espiritualidade e o apoio da família, seguidas, timidamente, de estratégias coletivas, estas centradas na boa relação com os colegas de trabalho e discentes, que são responsáveis por ressignificar as práticas laborais, contudo requerem mais investimento das instituições. Tais achados geram preocupação, uma vez que se entende que é na coletividade que ocorre a cooperação, a relação empática, a dialogicidade e a transformação da realidade laboral.
\end{abstract}

Palavras-chave: estratégias de defesa, sofrimento psíquico, docentes, saúde do trabalhador.

Defensive strategies against suffering at work by stricto sensu postgraduate professors

The study aimed to identify the defensive strategies against suffering at work developed by stricto sensu graduate professors. It was a descriptive research with a qualitative approach. Forty-seven professors from a university in the South of Brazil participated, who answered a questionnaire based on the Inventory on Work and Illness Risks, two representatives from each of the university's seven stricto sensu graduate programs were also interviewed. The investigation was approved by the institution's Ethics Committee and data collection took place between October 2018 and March 2019. Professors use, predominantly, individual defense strategies, among them are psychotherapy, religiosity/spirituality and family support, shyly followed by collective strategies, these centered on a good relationship with co-workers and students, who are responsible for giving new meaning to work practices, however they require more investment from the institutions. Such findings generate concern once it is understood that it is in the collectivity that occurs cooperation, empathic relationship, dialogicity, and transformation of work reality.

Keywords: defensive strategies, psychic suffering, professors, worker's health.

\footnotetext{
${ }^{1}$ https://orcid.org/0000-0003-3697-4109

${ }^{2}$ https://orcid.org/0000-0002-7119-0230

${ }^{3}$ https://orcid.org/0000-0002-2664-9292

${ }^{4}$ https://orcid.org/0000-0002-5163-4789

${ }^{5}$ https://orcid.org/0000-0002-4475-1725
} 


\section{Introdução}

intensificação do trabalho, o acirramento da competitividade e as exigências pelo configurações estabelecidas pelo mundo do trabalho, que geram cobranças, provocando tensão, desconfortos e adoecimento laboral (Araújo et al., 2016; Assunção \& Abreu, 2019).

A austeridade econômica no contexto produtivo e os novos valores culturais, tais como imediatismo, individualismo, narcisismo e consumismo, afetam as relações e a saúde humana (Leite \& Nogueira, 2017; Bauman, 2001). Essas mudanças geram nos profissionais imediatismos resolutivos e aceleração permanente, em busca de produtividade e competência (Cirani, Campanario, \& Silva, 2015). Ainda, obrigam o desenvolvimento de estratégias de defesa que deem conta dos desconfortos causados pelo impacto negativo do trabalho (Gouvernet, Mouchard, \& Combaluzier, 2015; Dejours, Deranty, Renault, \& Smith, 2018; Assunção \& Abreu, 2019).

Tais aspectos interferem na saúde e na qualidade de vida de muitas categorias profissionais, incluindo os docentes que atuam no ensino superior (Leite \& Nogueira, 2017). No que tange à pós-graduação, a intensificação do trabalho e as exigências pela geração de conhecimento científico passam a ser sentidas pelos docentes durante suas atividades cotidianas, culminando no sentimento contínuo de acúmulo de responsabilidades (Hoffmann, Marchi, Comoretto, \& Moura, 2018; Moreira, Tibães, \& Brito, 2018).

As exigências que despertam sensações de sofrimento, incertezas e angústias, fruto da fragilidade humana, somadas à necessidade de responder à mobilização emocional que disso resulta, posicionam os profissionais frente a situações que exigem estratégias e manejos psicológicos, a fim de conviver e lidar com sua rotina de trabalho (Cano \& Moré, 2016; Dejours, 2017; Valadão \& Neto, 2019).

As investigações realizadas no mundo do trabalho mostram que a adesão às estratégias de defesa produz custo psíquico elevado (Cano \& Moré, 2016; Dejours, 2017). Essas estratégias são específicas para cada local, produzidas, estabilizadas e mantidas individual e/ou coletivamente (Dejours, 2015, 2017).

Investigar estratégias de defesa utilizadas pelos docentes que atuam na pós-graduação stricto sensu requer olhar para uma categoria profissional que representa, atualmente, 100.287 trabalhadores brasileiros (Capes, 2019). No entanto, ainda se observa pouca mobilização no intuito de compreender como esses profissionais desenvolvem tais mecanismos de defesa frente às situações desgastantes do processo laboral (Araújo et al., 2016). Assim, tomando em consideração o exposto, indagou-se: quais estratégias de defesa são utilizadas por docentes da pós-graduação stricto sensu e como elas contribuem para lidar com o sofrimento no trabalho? Para responder a tal questão, o objetivo da pesquisa apresentada neste artigo foi identificar as estratégias de defesa do sofrimento no trabalho desenvolvidas por docentes da pós-graduação stricto sensu.

A investigação ancorou-se no referencial da Psicodinâmica do Trabalho, reconhecida como a teoria que estuda as formas de organização, as relações e os processos de trabalho 
(Dejours et al., 2018). Os estudos psicodinâmicos se dedicam a compreender as dimensões capazes de afetar profundamente as relações e a organização do trabalho, que geram consequências para a saúde dos trabalhadores.

Os fundamentos dejourianos revelam a existência de estratégias individuais e coletivas de defesa, que são definidas como recursos construídos pelos trabalhadores para minimizar a percepção do sofrimento no trabalho. As estratégias individuais têm papel determinante na adaptação ao sofrimento. Se, mesmo nesse caso, a vivência do sofrimento permanece fundamentalmente singular, as defesas podem ser objeto de cooperação. As estratégias coletivas de defesa contribuem, de maneira decisiva, para a coesão do coletivo de trabalho, pois trabalhar é não apenas ter a responsabilidade de desenvolver uma atividade, mas também viver: viver a experiência da pressão, viver em comum, enfrentar a resistência do real, construir o sentido do trabalho, da situação e do sofrimento (Dejours, 2007, 2008, 2011).

\section{Método}

Trata-se de um estudo qualitativo descritivo, uma vez que buscou identificar a intensidade e a complexidade do fenômeno do enfrentamento do sofrimento docente e sua dimensão sociocultural, além da compreensão detalhada dos significados e características situacionais apresentadas pelos participantes (Minayo, 2017).

A coleta de dados ocorreu entre os meses de outubro de 2018 e março de 2019 e a pesquisa cumpriu integralmente as Resoluções no 466 e no 510 do Conselho Nacional de Saúde (Ministério da Saúde, 2012, 2016), sendo aprovada pelo Comitê de Ética da Instituição (parecer n⿳⺈ 2.799.056/2018).

Participaram do estudo 47 docentes, homens e mulheres com média de idade de 46,5 anos, que atuavam havia 15 anos na docência, mas somente há quatro anos na pós-graduação. Exerciam suas atividades em sete programas de pós-graduação stricto sensu, em uma universidade do Sul do Brasil. Dentre eles, 14 foram selecionados para uma segunda etapa do estudo. Os critérios de inclusão utilizados foram: ser docente permanente de programa de pósgraduação stricto sensu e atuar por, no mínimo, um ano completo nessa atividade. Foram excluídos os profissionais afastados das atividades no período da coleta de dados e aqueles envolvidos no estudo.

A pesquisa focalizou todos os programas de pós-graduação stricto sensu da universidade, das áreas de Ciências Humanas, Ciências Sociais Aplicadas, Ciências da Saúde, Engenharia, Ciências Biológicas, Ciências Agrárias e Ciências Exatas e da Terra.

Na primeira etapa, os 67 docentes que se enquadravam nos critérios de inclusão do estudo foram convidados a responder o Inventário sobre Trabalho e Riscos de Adoecimento (ITRA), um instrumento que avalia os riscos de adoecimento no trabalho (Mendes \& Ferreira, 2007). Foram utilizados para este manuscrito os achados qualitativos oriundos de questões do instrumento que envolviam as estratégias de defesa, além dos dados oriundos do Questionário de Dados Sociolaborais e de Condições de Saúde do instrumento. Nessa etapa, 47 docentes contribuíram com o estudo. 
Na segunda etapa, foram sorteados dois docentes de cada programa, totalizando 14, para responder a uma entrevista com roteiro semiestruturado, contendo questões sobre a organização e os processos de trabalho do exercício da docência e sobre as estratégias de defesa utilizadas pelos participantes para enfrentar as situações geradoras de sofrimento no ambiente de trabalho. O conteúdo da entrevista foi elaborado a partir do referencial da Psicodinâmica do Trabalho, englobando aspectos como a compreensão de prazer e sofrimento no trabalho; sentidos e expectativas dadas ao trabalho; narrativa das atividades, demandas e do contexto da prática docente; situações e repercussões dos fenômenos estudados, bem como formas de enfrentamento e comentários para contribuir com o estudo. No conjunto, buscou-se compreender o importante papel das estratégias de defesa na adaptação ao sofrimento sentido e relacionado ao trabalho (Dejours, 2011, 2015).

Os dados do ITRA e do Questionário de Dados Sociolaborais e de Condições de Saúde foram coletados via aplicativo Google Forms, enviado para os e-mails institucionais dos participantes. Para aqueles que não participaram por meio dessa ferramenta, foi entregue o instrumento em cópia física. As entrevistas foram agendadas em local e horário sugeridos pelos profissionais, tiveram duração média de 30 minutos e foram gravadas e transcritas na íntegra. $\mathrm{O}$ número previsto de entrevistas mostrou-se suficiente uma vez que atingiu o critério de saturação, uma vez que não trouxeram elementos e esclarecimentos novos para o objeto estudado (Minayo, 2017).

Os dados oriundos do ITRA e do questionário foram interpretados qualitativamente, buscando identificar os riscos de adoecimento no trabalho dos docentes da pós-graduação stricto sensu, bem como as características sociolaborais do grupo estudado, para as quais também se recorreu à estatística descritiva básica, utilizando-se as medidas de médias e frequências.

Para a análise das entrevistas, foi utilizada a análise temática (Bardin, 2016), dividida em três etapas: pré-análise, exploração do material e tratamento dos resultados obtidos, que foram inferidos a partir do arcabouço teórico da Psicodinâmica do Trabalho. Tal procedimento permitiu, a partir da análise interpretativa, delinear as macrocategorias: estratégias de defesa individuais e estratégias de defesa coletivas do sofrimento no trabalho docente na pósgraduação stricto sensu.

Para resguardar o sigilo e o anonimato dos participantes, optou-se por identificá-los com nomes de pedras.

\section{Resultados e discussão}

Participaram da primeira etapa do estudo 47 docentes de diferentes áreas: Ciências Exatas e da Terra (um); Ciências Humanas (13); Ciências Sociais Aplicadas (12); Ciências Agrárias (dois); Ciências Biológicas (cinco); Ciências da Saúde (nove) e Engenharia (cinco). Com média de idade de 46 anos, com mínima de 31 e máxima de 58 anos, sendo que a maioria foi de homens $(61,7 \%)$, possuía companheiro/a $(89,4 \%)$ e filhos/as $(72,3 \%)$. A média de tempo na docência foi de 15 anos, destes, quatro na pós-graduação e $71,7 \%$ possuíam titulação de doutores. 
A interpretação do ITRA permitiu identificar que 22 (46,8\%) profissionais mencionaram algum sintoma que sugere alteração de saúde física ou emocional, 21 (44,7\%) associam tal sintoma ao trabalho e $14(29,5 \%)$ afirmam tomar medicamentos para superar as condições adversas do trabalho.

Para que os dissabores oriundos das práticas laborais sejam reelaborados pelos docentes, permitindo que eles continuem trabalhando, surgem as estratégias de defesa que, de acordo com a Psicodinâmica do Trabalho, atuam principalmente nos momentos em que o sofrimento invade o contexto laboral (Dejours, 2017; Dejours et al., 2018).

De acordo com a Psicodinâmica do Trabalho, a interação do sujeito com a organização do trabalho é a responsável por despertar ora o prazer, ora o sofrimento (Dejours, 2017). Quando essa relação resulta em desconforto, surgem as estratégias de defesa, as quais podem ser individuais ou coletivas, utilizadas para lutar contra o sofrimento psíquico que o fato de trabalhar em um clima de ameaça implica. O sofrimento, sobre o qual as estratégias de defesa tentam assumir o controle mental, está intimamente ligado às exigências organizacionais do trabalho (Dejours, 2015, 2017; Amaral, Borges, \& Juiz, 2017; Hoffmann, Zanini, Moura, Costa, \& Comoretto, 2017; Oliveira, Almeida, Souza, Pires, \& Madriaga, 2017).

Nesse sentido, buscou-se, com as entrevistas, identificar também as estratégias de defesa utilizadas pelos docentes frente ao sofrimento no trabalho. Nessa etapa, os resultados foram agrupados nas duas macrocategorias apresentadas na Figura 1, bem como as subcategorias, a partir da análise das entrevistas com os docentes.

Figura 1: Subdivisão das estratégias de defesa individuais e coletivas dos docentes da pósgraduação

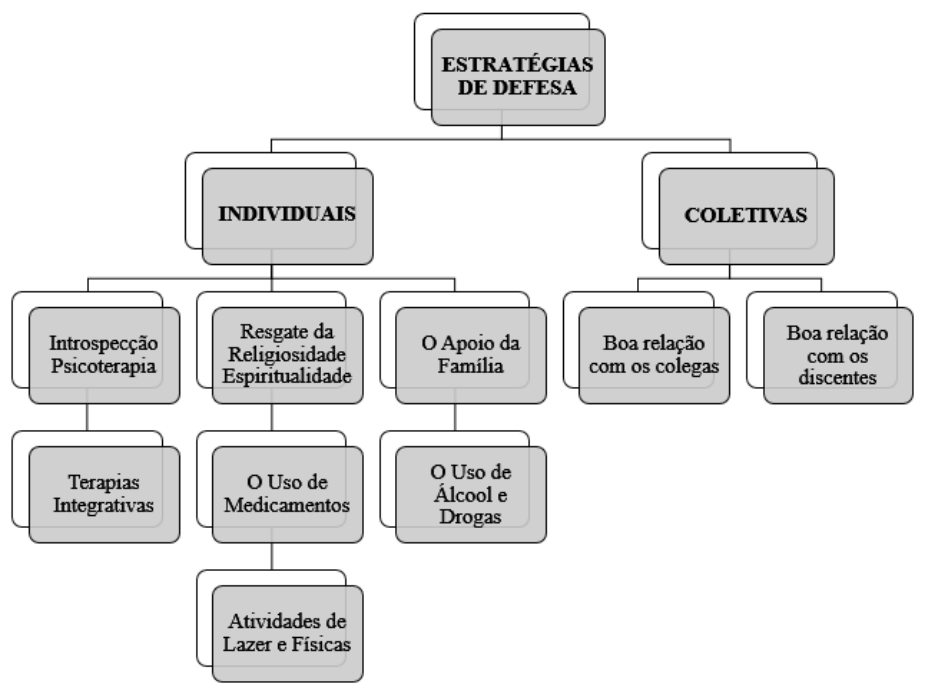

Fonte: Elaboração dos autores (2019).

\section{As estratégias de defesa individuais utilizadas pelos docentes na pós-graduação}

As estratégias de defesa individuais são um processo dinâmico que as pessoas criam para se proteger dos conflitos no funcionamento psíquico ocasionados pelo sofrimento gerado 
nos locais de trabalho. Tais estratégias têm importante papel na adaptação ao sofrimento e são destinadas, portanto, a lutar em prol do equilíbrio psíquico (Dejours, 2017). Essa eufemização do sofrimento possibilita uma proteção ao psiquismo, tornando possível que os trabalhadores continuem exercendo suas funções laborais (Loureiro, Mendes, \& Silva, 2018). O conjunto das diferentes estratégias apresentadas pelos docentes, bem como o predomínio de estratégias individuais, revela o esforço psíquico que eles fazem para mediar as demandas do trabalho.

Identificou-se que os docentes desenvolvem estratégias de defesa individuais para controle e adaptação frente às demandas do exercício e às situações desgastantes. Tais estratégias são sutis, além de necessárias à vida e à proteção da integridade psíquica e somática desses trabalhadores (Dejours, 2007; Silveira, Enumo, \& Batista, 2014; Amaral et al., 2017; Pietrowski, Cardoso, \& Bernardi, 2018; Tundis, Monteiro, Santos, \& Dalenogare, 2018; Valadão \& Neto, 2019).

A necessidade de recuperar estratégias de defesa individuais, caracterizadas por esforços comportamentais e cognitivos, é exercitada pelos docentes a fim de equilibrar as exigências dos processos de trabalho, bem como de reduzir, eliminar ou reelaborar os desconfortos causados pelo ofício (Valadão \& Neto, 2019). Contudo, essas estratégias não se voltam para o problema em si, mas para os recursos pessoais, sendo, assim, pouco capazes de alterar o contexto ou as questões que levam ao sofrimento, muitas vezes alcançando o coletivo dos trabalhadores ou uma parte deles.

Diferente de resultados encontrados em outras pesquisas (Leite \& Nogueira, 2017; Loureiro et al., 2018), os docentes deste estudo afirmaram que o distanciamento do trabalho se torna oportuno para que o profissional se reinvente e encontre novos sentidos a sua prática profissional. Além disso, sinalizam que momentos de solidão e de recolhimento são fundamentais para seguir na atividade. Os depoimentos a seguir ilustram esse aspecto:

Em casa eu tenho um tempo dedicado pra mim. O momento da solidão e do silêncio são realidades imprescindíveis, do ponto de vista de poder me inteirar, me compenetrar nas coisas (...). Para a própria existência, a solidão é decisiva (...). Os professores, todo o mundo, deveria ter uma zona de solidão muito própria, que fosse uma coisa inegociável. Consegue entender isso? Porque a solidão, ela não é para mim um problema, não é uma coisa que me deixa na fossa, deprimido. Muito pelo contrário, aliás, se eu não tiver isso, é aí que eu entro (em depressão). Entende? (Rubi).

...às vezes eu me recolho. Não gosto de ir para enfrentamentos, sem antes elaborar as coisas. Então, de maneira geral, eu elaboro (...). Dificilmente eu vou para um enfrentamento assim e falo coisas que depois me arrependo (Alexandrita).

Estudos psicodinâmicos mencionam que até mesmo as pessoas dotadas de uma sólida estrutura psíquica podem ser vítimas de uma paralisia mental, induzida pela organização do trabalho e que são necessárias estratégias de defesa individuais como essas mencionadas pelos docentes para enfrentar o labor (Dejours, 2015, 2017; Dejours et al., 2018). Também se utilizam da psicoterapia, entendida como um serviço psicológico conduzido por profissional da psicologia, que se fundamenta, principalmente, em formas de comunicação e interação para avaliar as reações emocionais, pensamentos e comportamentos, como ferramenta capaz de 
auxiliá-los no seu processo de (re)conhecimento e de busca pela saúde (American Psychological Association, 2010).

Eu tive a graça de fazer 11 anos de psicanálise de divã e três anos de terapia. Então, essa travessia me ajudou muito. Eu tive uma terapeuta que me ajudou a ser professor, foi decisiva na minha vida e me ajudou a lidar com essas frustrações. (...) descobrir de uma forma mais potencializada e saudável a própria dimensão da solidão, da falta. (...) Eu sempre dizia para a minha psicanalista: "olha, esse itinerário me põe num lugar que, para mim, é um lugar que eu não posso negociar com ninguém. Que é esse lugar do vazio absoluto. E esse lugar não é um lugar fácil, ele é um lugar assustador, ele é um lugar que aterroriza!" (Rubi).

Doeu muito quando eu me dei conta, porque eu via muito nas pesquisas essas questões de estratégias individuais de enfrentamento. E é isso minha cara, de modo geral, é individualmente que a gente tem que lidar, fazendo psicoterapia, tentando levar uma vida um pouco mais saudável (Turquesa).

A Psicodinâmica do Trabalho indica que é comum os trabalhadores utilizarem mecanismos de defesa, isto é, recursos da mente para evitar o sofrimento originado na consciência pelos conflitos intrapsíquicos entre os desejos e as proibições. Seu objetivo é afastar da consciência o que a pessoa não aceita, fazendo com que essas defesas promovam "disfarces", a fim de permitir a diminuição de carga psíquica, tornando as respostas físicas e emocionais equilibrantes (Dejours, 2015).

Estudos como os de Maturana e Valle (2014), Alves e Lima (2016), Araújo et al. (2016), Cano e Moré (2016), Dalcin e Carlotto (2018), Ferreira (2019) revelam que a psicoterapia é uma estratégia muito utilizada pelas pessoas para o autoconhecimento, capaz de despertar o processo de aprendizagem para lidar com situações cotidianas. Por meio dela, as pessoas passam a identificar suas fragilidades e potencialidades na maneira como conduzem seus processos diários, inclusive os laborais, compreendendo as diferenças que existem nas relações, nos pensamentos, nas atitudes e na sua forma de sentir.

Para a Psicodinâmica do Trabalho, escutar dos profissionais o que é tramado em torno da relação com o trabalho corresponde a ouvir as ramificações e os desdobramentos a que eles estão expostos. As estratégias apresentadas pelos docentes remetem a investimentos emocionais, afetivos, cognitivos que esses sujeitos projetam em seu labor e quais as consequências disso na esfera de sua subjetividade (Dejours, 2017; Dejours et al., 2018).

Eu já pensei em procurar ajuda, psicoterapia. (...) Estou pensando de novo em ir buscar ajuda, porque eu sempre lidei com as minhas dificuldades, com os meus medos, com os meus temores, mas eu acho que estou chegando em um momento que não consigo mais resolver sozinha. Não estou conseguindo mais estancar essas coisas. Então, eu estou aqui conversando contigo, nunca te vi antes, e estou me emocionando. Isso significa dizer que isso está me fazendo mal. E eu sempre disse que, se um dia começasse a me fazer mal, ia pensar em outras coisas, mas ainda não consigo (...). Eu ando bem desapontada sabe? Hoje, ando bem frustrada, ando bem triste. Eu acho até que ando depressiva, sabe? (...) tenho chorado, (...) ando desencantada (Berilo). 
Cabe observar que um mesmo recurso pode ser utilizado com intensidades e motivos diferentes por cada trabalhador, requerendo, dessa forma, observar o quanto auxiliam no alcance da mediação do sofrimento, o que repercute no potencial de adoecimento e esgotamento.

No trabalho docente, esse esgotamento oriundo do trabalho é o cerne de estudos nacionais e internacionais (Martinéz, 1997; Codo, 2006; Forattini \& Lucena, 2015; Hoffmann et al., 2017; Facci, Urt, \& Barros, 2018; Tundis \& Monteiro, 2018; Baptista, Soares, Raad, \& Santos, 2019) que discutem a exaustão física e mental associadas à precarização das condições trabalho. Outros estudos (Cupertino, Garcia, \& Honório, 2015; Monsalve, 2016; Davoglio, Spagnolo, \& Santos, 2017; Leite \& Nogueira, 2017; Oliveira et al., 2017; Oliveira, Pereira, \& Lima, 2017; Souto et al., 2017; Ferreira, Ferenc, \& Wassem, 2018; Hoffmann et al., 2018; Tundis et al., 2018; Fernández, Navarro, \& Fierro, 2018) revelam, ainda, um crescente processo de desgaste físico e emocional dos docentes universitários, os quais têm seu cotidiano atravessado pela sobrecarga de trabalho. Por vezes, as falas dos docentes indicam o sofrimento já instalado, naturalizado no macrocenário social. A intensidade da jornada na universidade, potencializada pela pós-graduação, repleta de exigências dos órgãos de fomento e de avaliação, tornam esse contexto de trabalho potencialmente desgastante. Comumente, as cobranças por resultados quantitativos e qualitativos, que, em vários momentos, desconsideram as capacidades dos docentes de forma singular e as demandas acumuladas, culminam na necessidade de mobilizar o emocional, o que, ao longo do tempo, promove o sofrimento psíquico confirmado nesta e em outras investigações.

Também são desenvolvidas estratégias de defesa por meio do resgate da religiosidade e da espiritualidade, sustentadas por práticas e/ou elementos sagrados, que auxiliam na resposta emocional a eventos desgastantes enfrentados no decorrer da vida. No âmbito das discussões sobre a importância da religiosidade/espiritualidade para enfrentamento do sofrimento, sob a ótica de diferentes referenciais teóricos, autores atestam que essas são essenciais para que as pessoas busquem sentidos e atribuam significados ao que é vivido (Silveira et al., 2014; Borges, Santos, \& Pinheiro, 2015).

No âmbito do cristianismo, eu tomei uma decisão já há muito tempo na minha vida, de me mover nessa esfera. Então, eu coloco toda essa dimensão naquilo que nós chamamos do âmbito da oração. A oração enquanto esse lugar da pura falta, é um lugar onde eu me equaciono, das minhas tensões, das minhas dores (...), dessa não potência de poder fazer as coisas. Daí, eu vou, eu volto, vou e volto permanentemente. Então, aí que eu ponho as minhas frustrações, os meus desconfortos, as minhas taras, os meus limites, enfim (Rubi).

Como encontrar o equilíbrio nesse momento? Graças a Deus, eu consigo me manter bem. Espiritualmente, eu procuro estar conectado (Safira).

Tais práticas auxiliam na redução da ansiedade, no aumento de esperanças e na atribuição de significado da existência. Alguns comportamentos e crenças religiosas e espirituais são experiências que estão diretamente relacionadas à felicidade geral e à saúde física 
(Reis \& Menezes, 2017). Compreendida como um lugar de emponderamento, a conexão com a espiritualidade emerge para muitos indivíduos como um recurso que promove bem-estar, como evidencia-se em alguns relatos dos docentes. Essas práticas religiosas podem ser compreendidas como uma função mediadora na relação entre situações geradoras de desconforto e a presença de sofrimento, contribuindo para a reestruturação cognitiva dos docentes, bem como para o estabelecimento de práticas voltadas à solução de desafios no cotidiano de trabalho (Silveira et al., 2014). Por outro lado, assim como outras estratégias individuais, tais práticas podem sinalizar tentativas de negação ou impossibilidade de lidar com o sofrimento, processando-o no nível da naturalização ou evitando-o.

As vivências no trabalho ultrapassam os limites de espaço e de tempo relacionadas ao exercício laboral. A intensificação da atividade influencia o comportamento das pessoas, viabilizando vivências de desgaste, tensão e ansiedade, afetando a vida dentro e fora do cenário laboral (Araújo et al., 2016; Ruza \& Silva, 2016; Leite \& Nogueira, 2017; Oliveira et al., 2017; Ferreira et al., 2018; Loureiro et al., 2018; Tundis \& Monteiro, 2018; Hoffmann et al., 2018). Os docentes sinalizam que as famílias são âncoras significativas para que possam manter-se na profissão.

Os meus filhos são uma espécie de âncora muito significativa que eu tenho. Então, eu acho que ali tem uma válvula de escape muito boa (...). Isso me dá uma proximidade muito grande com eles, de estar com, de brincar com, de jantar com, de fazer coisas com (Diamante).

Eu dou conta de muitas coisas porque tenho um marido que é muito parceiro. Então, se ele tiver que fechar a porta e me trazer um chá e me trazer uma fruta, em silêncio, sem exigir nada, ele faz. Faz muitas vezes (...), me ajuda, me ajuda muito. Eu não aguentaria se fosse diferente (Alexandrita).

O trabalho repercute na subjetividade daquele que trabalha, pode envolver os demais membros da família e as relações em torno do sujeito (Dejours, 2012). A onipresença da expressão 'desequilíbrio trabalho-vida' indica que as sociedades modernas atribuem muito valor ao trabalho, que superestimam os bens que o labor proporciona e que essa supervalorização tem consequências danosas para os trabalhadores e seus familiares (Dejours et al., 2018; Silveira \& Bendassolli, 2018). Ao longo das entrevistas, os docentes ponderaram, em momentos diferentes, as repercussões que os problemas do trabalho têm nas suas vidas pessoais, entre elas o afastamento dos filhos, os problemas conjugais, a ruptura com familiares e amigos. Cabe lembrar que esses trabalhadores, frequentemente, têm uma jornada estendida ao âmbito domiciliar, uma vez que lhes são impostos prazos e metas que, por vezes, são incompatíveis com o lazer e socialização.

As Práticas Integrativas Complementares (PIC) também foram mencionadas como estratégia, pois elas estão sendo cada vez mais utilizadas pelos trabalhadores como estratégias para auxiliar na redução do desgaste ocupacional, bem como na redução dos níveis de ansiedade e sintomas depressivos (Llapa et al., 2015): 
Houve um período que eu fiz alguns meses de reiki, porque a gente tenta, pelo menos, desacelerar ou se organizar um pouquinho melhor e tal. Já faz um tempo que eu não faço mais (...) (mas) já estou sentindo necessidade novamente (Painita).

Estudos que investigam como as terapias complementares podem contribuir para o bem-estar do trabalhador sugerem que elas colaboram para melhorar, tanto a saúde psicossocial no local de trabalho quanto potencializar o desempenho do trabalhador, uma vez que contribuem com o gerenciamento do desgaste ocasionado pela organização do trabalho, resultando em impacto positivo na construção da identidade do trabalhador (Silva \& Sales, 2016; Ravalier, Wegrzynek, \& Lawton, 2016). As PIC representam estratégias com elevado potencial de contribuir com a prevenção do adoecimento, promovem um cuidado delicado e não invasivo, especialmente interessante para os trabalhadores com ritmo acelerado de trabalho, a exemplo dos docentes no stricto sensu. Elas também podem ser uma alternativa para evitar o uso excessivo de medicamentos.

Na América Latina, tem sido registrado um nível expressivo de adoecimento docente (Diehl \& Marin, 2016; Ruza \& Silva, 2016; Bataier, Pegorete, Lawall, \& Calvacanti, 2017; Hoffmann et al., 2017; Penteado \& Neto, 2019; Araújo, Pinho, \& Masson, 2019; Medeiros \& Vieira, 2019). Nesse contexto, a medicalização (Cano \& Moré, 2016; Ruza \& Silva, 2016; Bataier et al., 2017) é uma estratégia muito utilizada pelos profissionais para superarem as condições adversas do trabalho. No grupo estudado, o uso de medicamentos, apresentado na Figura 2, também apareceu como estratégia de defesa individual utilizada pelos profissionais.

Figura 2: Categoria de medicamentos utilizadas pelos docentes da pós-graduação

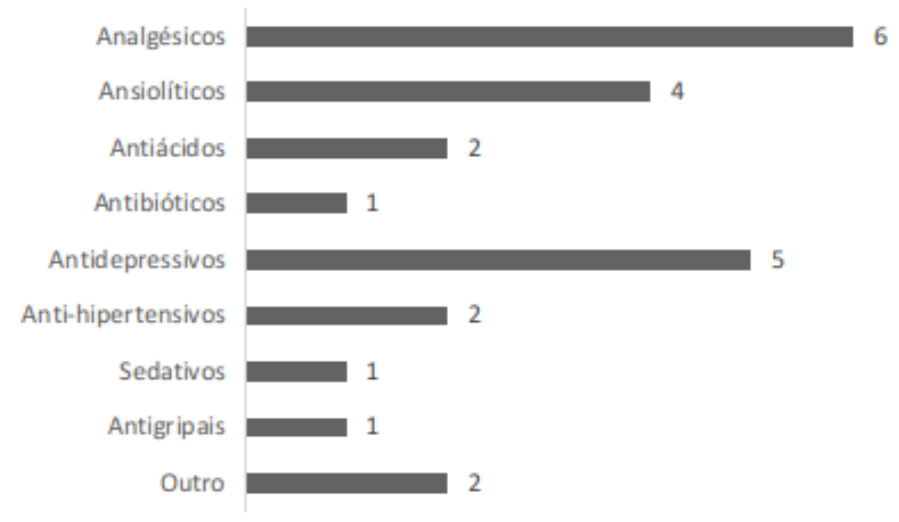

Fonte: Elaboração dos autores (2019).

Os relatos a seguir exemplificam como a medicação tem sido utilizada pelos docentes:

...a razão de ter muitas atividades me causa problemas de ansiedade. Eu tenho problema de insônia. (...) É um somatório de fatores, então eu uso medicações para dormir (Cristal). 
Teve um momento nesse ano, que eu acho que foi estresse de trabalho associado a problemas de casa. Eu tive uma crise de enxaqueca. Eu nunca antes tive enxaqueca na minha vida, sempre aquela dor de cabeça leve, que tu toma um medicamento e resolve. Eu tinha prazo para enviar o projeto até a meia noite e era de manhã e não estava com o projeto pronto (...) e eu fiquei 15 dias com uma enxaqueca. Fui para o hospital cinco vezes (Âmbar).

Aos olhos da Psicodinâmica do Trabalho, a medicalização visa à desqualificação do sofrimento mental, além do deslocamento do conflito homem-trabalho para um terreno mais neutro (Dejours, 2015; Dejours et al., 2018). Uma prova a mais da intensidade desse conflito no trabalho é fornecida pelos problemas de sono e, sobretudo, pelo consumo de medicamentos psicotrópicos pela maioria das pessoas: ansiolíticos durante o dia, soníferos à noite e psicoestimulantes pela manhã (Dejours, 2015). Entretanto, mesmo fora da situação de trabalho, tais sintomatologias aparecem camufladas sob a forma de vertigens, cefaleias e demais impotências funcionais (Dejours, 2017). Na medida que esses medicamentos imperam sobre a vida dos docentes, camuflando as tensões oriundas do trabalho, os profissionais acabam por não identificar que tais fármacos representam "máscaras" que agravam os desconfortos e impactos causados pelo que é experienciado no trabalho.

O uso de álcool também apareceu como uma estratégia de defesa individual para lidar com as obrigatoriedades exigidas pela profissão: "Eu posso, enfim, tomar uma cerveja, um vinho. Então é um período que eu procuro me libertar mais da questão da obrigatoriedade, né? Acho que aí o vinho ajuda bastante também, o vinho e a cerveja" (Diamante). As exigências ocupacionais são fatores que desencadeiam fortemente o aparecimento de comportamentos individuais específicos no trabalho. Uma das saídas frente à ansiedade laboral concreta é o uso de álcool, que atinge um número expressivo de trabalhadores (Dejours, 2015), sendo uma estratégia individual gravemente condenada pelos grupos sociais.

Na docência, esse fenômeno é retratado em diversos estudos que destacam a exaustão emocional que acomete esses profissionais, fazendo com que desenvolvam estratégias centradas na emoção e, nesse processo, o uso de álcool e drogas é uma das encontradas para lidar com as adversidades laborais (Bueno, Bravo, Feraudy, Lima, \& Takayanagui, 2011; Barbosa \& Fonseca, 2019). Para os fundamentos dejourianos, o uso de drogas corresponde a uma fuga em direção a uma decadência mais rápida e a um destino mental e somático particularmente grave de quem trabalha (Dejours, 2015). Nesse sentido, compreendendo a relação das drogas com processos humanos subjetivos, pode-se dizer que essa ligação é interpretada como um refúgio da realidade vivida, sendo recurso para minimizar o mal-estar vivenciado.

Ainda, os docentes mencionaram as atividades de lazer como estratégias, com destaque para leituras, passeios, viagens e atividades com amigos. Tais atividades são compreendidas por eles como fortalecedoras de valorização do ambiente extra laboral (Araújo et al., 2016).

Eu tento, às vezes, esquecer, por exemplo, fazer uma atividade totalmente fora da instituição, ter os momentos de prazer, os momentos que você consegue desconectar. Então, por exemplo, se dar ao luxo de por um período não abrir o e-mail, por quê? Porque eu sei que vai me trazer mais atividades, de eu poder sair, de eu poder passear, de eu poder viajar, de assistir um filme, de conviver com as pessoas que eu gosto. Então, são escapes que a gente utiliza obviamente, fora o período de trabalho, mas que 
auxiliam na verdade a você diminuir o seu nível de estresse. Assistir um bom filme, ler um bom livro, viajar, passear, visitar um amigo, coisas nesse sentido (Azurita).

Eu procuro sair com uma atividade com os amigos, para passear (Rubi).

Agora eu estou fazendo um exercício, de que eu tenho que ter amizades fora do trabalho, porque eu sempre fui muito trabalho. Então, as minhas amizades eram todas do trabalho, tudo girava em torno do trabalho e, agora, eu tenho feito um exercício de sair com pessoas que não são da área (Topázio).

Além disso, os docentes reconhecem os efeitos da atividade física e do exercício físico para a promoção e manutenção da saúde em seus vieses físicos e psicológicos, sendo que muitos se utilizam dessa estratégia para seu benefício e desenvolvimento psicossocial.

Uma das estratégias que eu utilizo, mesmo estando com todos esses afazeres é tentar tirar um tempo, mesmo que seja curto, trinta minutos, para estar comigo mesmo, tipo uma caminhada, (...) me ajuda a descarregar um pouco. (...) A gente lê bastante e, depois que eu li um livro, não consigo me lembrar o nome da..., que é vidas concorridas, algo assim (...). Eu tive uma outra visão, que a gente tem que se cuidar. Então, foi nesse momento também que eu parei para começar a fazer essas questões (...). Essa é uma forma que eu tenho para tirar essa ansiedade (Jade).

Existem benefícios da prática de atividades físicas e exercícios físicos que se inclinam para a proteção e promoção da saúde integral dos docentes. Tais achados, também encontrados em outro estudo (Santos, Maia, Claro, \& Medeiros, 2019), sinalizam a propensão dos docentes à adesão de um estilo de vida que proporcione bem-estar físico e emocional.

\section{As estratégias de defesa coletivas dos docentes da pós-graduação}

As estratégias de defesa coletivas auxiliam quem trabalha a suportar uma realidade que não conseguiria tolerar isoladamente, com suas próprias defesas, assim como também favorecem, nas práticas laborais, a coesão e estabilização dos coletivos de trabalho. Com isso, quando as pessoas experimentam o sofrimento, são capazes de se unir e construir uma estratégia defensiva comum, funcionando com regras que precisam da anuência dos indivíduos coletivamente e que podem ter o seu funcionamento interrompido quando eles não o desejarem mais.

Existem muitas estratégias de defesa coletivas, que são específicas para situações de trabalho (Maturana \& Valle, 2014; Araújo et al., 2016; Cano \& Moré, 2016; Dejours, 2017; Silva \& Piolli, 2017; Dejours et al., 2018; Loureiro et al., 2018; Silveira \& Bendassolli, 2018). Atuando como um acordo entre os membros do coletivo, as estratégias de defesa coletivas se empenham por manter em equilíbrio as relações do trabalho, bem como sua organização (Vieira, Mendes, \& Merlo, 2013). Por meio destas é que surge a estabilidade e a proteção ao psiquismo, como ilustram os participantes: 
(...) eu circulo em dois espaços, que nós temos grupos muito legais, tanto no mestrado quanto na graduação. Eu tenho muitos amigos, são grupos em que eu me sinto bem. Isso também é um fator de apoio, de prevenção, digamos assim. Então, a gente consegue trocar, sem que seja pra se lamentar ou consegue se apoiar de alguma forma. Mas tem grupos em que isso não acontece... (Turquesa).

Na instituição, há uma relação interpessoal com os colegas que pode ser rica. Esse é um traço meu. Eu vou para o outro muito, muito espontaneamente e sempre, na maioria das vezes, nem sempre, muito ingênuo pela recepção do outro (Rubi).

As falas ilustram a importância do conforto encontrado nas relações que o trabalho oferece. Os docentes, ao sentirem-se compreendidos por outros que experienciam processos de trabalho semelhantes aos seus, conseguem criar vínculos capazes de resultar em uma rede de apoio e suporte.

Esses achados convergem com estudos que retratam que é comum os profissionais buscarem por apoio social, recorrendo aos colegas quando as dificuldades e problemas se referem ao trabalho. Afinal, eles geralmente são comuns a todos naquele cenário laboral (Cano \& Moré, 2016; Dejours et al., 2018; Tundis et al., 2018; Valadão \& Neto, 2019). Utilizado para solucionar alguma questão específica, o apoio dos colegas auxilia a compartilhar angústias, trazendo conforto e sustentação emocional. Por outro lado, algumas investigações afirmam que a relação entre os colegas pode causar o sofrimento no trabalho e caracterizar uma das dimensões da síndrome de burnout, dificultando os processos e a organização do trabalho (Silva, Menezes, \& Cassunde, 2016; Pietrowski et al., 2018; Baptista et al., 2019; Ferreira, 2019).

O sofrimento sobre o qual as estratégias de defesa coletivas tentam assumir o controle mental está sempre intimamente ligado às exigências organizacionais e às relações do trabalho (Dejours, 2017). Aqueles que sofrem por causa da degradação progressiva das relações de trabalho (arbitrariedade das decisões, desconfiança, individualismo, concorrência desleal entre colegas, arrivismo desenfreado), da intensificação do trabalho, por causa do aumento da carga de trabalho e da fadiga, encontram muitas dificuldades para reagir coletivamente (Dejours, 2007, 2011, 2015, 2017; Dejours et al., 2018). Ligado a isso, as pressões suscitadas nesse cenário geram desgaste e sofrimento, tencionam as relações, o que propicia a ausência de diálogos e dificuldade de tomada de decisão, fazendo emergir relações não harmoniosas, o distanciamento, além de disputas de âmbito pessoal e institucional.

Onde não tem espaço para diálogo, brota o espaço do sofrimento, brota o espaço da, como é que a gente chama aquela, ah, rancor, brota a inimizade, brotam coisas desnecessárias, que, muitas vezes, com uma boa conversa, elas seriam resolvidas (Diamante).

Há a necessidade de recuperar o diálogo entre os pares. Não há universidade se não houver diálogo, não há universidade, se não houver diálogo nas tomadas de decisões (Rubi). 
Possibilitadas pelo trabalho, as relações docente/discente são expressadas pelos profissionais como estratégias de defesa coletivas que estimulam seus fazeres laborais, visto que os vínculos estabelecidos ressignificam a prática e contribuem para cumprir as múltiplas exigências no trabalho, pois recorrem ao auxílio de outros com maior frequência e facilidade.

$\mathrm{Na}$ orientação você consegue estabelecer um vínculo mais próximo com o aluno (...). No stricto sensu, são turmas pequenas. Então, isso te permite ter um contato diferenciado com o aluno (Turquesa).

A gente tem estudantes ingressando, pessoas que têm interesse na sua formação, em se qualificar intelectualmente, melhorar sua leitura de mundo etc. A gente também tem que considerar que tem um espaço de pós-graduação que nos dá condições para muitas coisas. Condições para a gente estudar junto com os orientandos. Tentar produzir referenciais como livros, artigos, pesquisas etc. Nos permite ter contato com pessoas como tu, que está fazendo a pesquisa, e a gente pode dialogar sobre (Diamante).

A boa relação com os discentes é apresentada em outros trabalhos acadêmicos (Loureiro et al., 2018; Moreira et al., 2018) como uma estratégia de defesa coletiva que perpassa o cenário universitário. Essa relação é mediadora da redução de carga psíquica e torna o cotidiano do docente equilibrante. Nos cursos de mestrado e doutorado, evidenciou-se que o tempo de permanência e a proximidade com os estudantes repercute em relações de afeto e laços que perduram para além do ambiente acadêmico, o que traz o sentimento de ganho extra com as relações tecidas nesse espaço.

Autores ponderam que é necessário penetrar na vivência do indivíduo que trabalha, acessar as dimensões psíquicas e intelectuais do seu trabalho que residem em sua experiência e no registro de suas vivências subjetivas (Tundis et al., 2018; Dejours et al., 2018). As estratégias coletivas apresentam um maior potencial de mediar o sofrimento já que são construídas de forma conjunta. Mesmo que a vivência do sofrimento permaneça fundamentalmente singular, as defesas podem ser objeto de cooperação, além de representarem uma maneira decisiva para a coesão do coletivo de trabalho.

Além disso, sinaliza-se a importância das estratégias institucionais compreendidas como meios de compreender a totalidade e profundidade do universo docente, a fim de atuarem como redutoras de desconfortos e de promoverem melhores condições de trabalho.

\section{Considerações finais}

Os profissionais do estudo, majoritariamente homens, com companheiros e filhos, atuam em média há quatro anos na pós-graduação em áreas distintas. Docentes que expressam a multiplicidade de funções e as exigências do exercício na pós-graduação, marcadamente sofrem a influência das pressões por produtividade científica, balizada por prazos, além de diversas atividades com potencial de causar sofrimento. Com tudo isso, observou-se que os desafios no exercício docente obrigam esses profissionais a desenvolverem estratégias de defesa individuais e/ou coletivas como mecanismo de "sobrevivência", para que possam continuar 
trabalhando. Nesse sentido, foi identificado que as primeiras se centraram na introspecção, na psicoterapia, no resgate da religiosidade/espiritualidade. Ainda, os docentes recorrem ao apoio da família, às PIC, às atividades de lazer e físicas e, infelizmente, a recursos aditivos, como medicamentos, álcool e drogas.

As estratégias coletivas apareceram timidamente por meio da boa relação com os colegas de trabalho e com os discentes. Além disso, identificou-se a ausência de estratégias institucionais que sirvam de apoio para a compreensão da totalidade do universo docente, que atuem como redutoras de sofrimento psíquico e promovam melhores condições de trabalho e, consequentemente, propaguem o prazer laboral.

Ainda que o estudo notabilize as estratégias de defesa individuais e coletivas desenvolvidas pelos docentes, entende-se que ele tem limitações no que se referiu ao número de participantes e à temporalidade da coleta de dados. Deste modo, recomenda-se que sejam realizados outros estudos no contexto docente, bem como pesquisas longitudinais.

Por fim, de posse dessas reflexões, ancoradas nas contribuições da Psicodinâmica do Trabalho, sugere-se que sejam realizados novos estudos, em cenários mais amplos e com maior número de pessoas, objetivando investigar as estratégias de defesa no âmbito laboral, para que esse fenômeno seja compreendido com profundidade e singularidade.

\section{Referências}

Alves, V. L. P., \& Lima, D. D. (2016). Percepção e enfrentamento do psicossomático na relação médico-paciente. Psicologia: Teoria e Pesquisa, 32 (3), 1-9.

Amaral, G. A., Borges, A. L., \& Juiz, A. P. M. (2017). Organização do trabalho, prazer e sofrimento de docentes públicos federais. Cadernos de Psicologia Social do Trabalho, 20(1), 15-28.

American Psychological Association (2010). Dicionário de psicologia. Porto Alegre: Artmed.

Araújo, M. N. A., Rodrigues, C. C. F. M., Dantas, M. S. P., Santos, N. P., Alves, K. Y. A., \& Santos, V. E. P. (2016). Estresse no cotidiano universitário: estratégias de enfrentamento de docentes da saúde. Revista Online de Pesquisa, 8(4), 4956-4964.

Araújo, T. M., Pinho, P. S., \& Masson, M. L. V. (2019). Trabalho de professores e saúde no Brasil: reflexões sobre a história da pesquisa, avanços e desafios. Cadernos de Saúde Pública, 35 (suppl. 1), e00087318.

Assunção, A. A., \& Abreu, M. N. S. (2019). Pressão para o trabalho, estado de saúde e condições de trabalho dos professores da educação básica no Brasil. Cadernos de Saúde Pública, 35 (suppl. 1), e00169517.

Baptista, M. N., Soares, T. F. P., Raad, A. J., \& Santos, L. M. (2019). Burnout, estresse, depressão e suporte laboral em professores universitários. Revista Psicologia: Organização e Trabalho, 19(1), 564-570.

Barbosa, R. E. C., \& Fonseca, G. C. (2019). Prevalência de tabagismo entre professores da Educação Básica no Brasil, 2016. Cadernos de Saúde Pública, 35(suppl. 1), e00180217.

Bardin, L. (2016). Análise de conteúdo (edição revista e ampliada). São Paulo: Edições 70.

Bataier, V. S., Pegorete, T. R., Lawall, P. Z. M., \& Calvacanti, P. P. (2017). Automedicação entre docentes de nível superior. Revista Enfermagem Atual, 81(1), 11-18.

Bauman, Z. (2001). Modernidade líquida. Rio de Janeiro: Zahar.

Borges, M. S., Santos, M. B. C., \& Pinheiro, T. G. (2015). Representações sociais sobre religião e espiritualidade. Revista Brasileira de Enfermagem, 68(4), 609-616.

Bueno, M. D. P. N., Bravo, J. F., Feraudy, N. Y., Lima, P. P., \& Takayanagui, A. M. M. (2011). Conhecimento sobre o fenômeno das drogas entre estudantes e professores da Faculdade de Medicina da Universidade de San Andrés, La Paz, Bolívia. Revista Latino-Americana de Enfermagem, 19(1), 722-729. 
Cano, D. S., \& Moré, C. L. O. O. (2016). Estratégias de enfrentamento psicológico de médicos oncologistas clínicos. Psicologia: Teoria e Pesquisa, 32(3), 1-10.

Carlotto, M. S., \& Câmara, S. G. (2008). Síndrome de burnout e estratégias de enfrentamento em professores de escolas públicas e privadas. Psicologia da Educação, 26(1), 29-46.

Cirani, C. B. S., Campanario, M. A., \& Silva, H. H. M. (2015). A evolução do ensino da pós-graduação senso estrito no Brasil: análise exploratória e proposições para pesquisa. Avalição, 20(1), 163-187.

Codo, W. (2006). Educação: carinho e trabalho. Petrópolis, RJ: Vozes.

Capes (2019). http://www.capes.gov.br/estatísticas

Cupertino, V., Garcia, F. C., \& Honório, L. C. (2015). Prazer e sofrimento na prática docente no ensino superior: estudo de caso em uma IFES mineira. Trabalho $\mathcal{E}$ Educação, 23(3), 101-116.

Dalcin, L., \& Carlotto, M. S. (2018). Avaliação de efeito de uma intervenção para a síndrome de burnout em professores. Psicologia Escolar e Educacional, 22(1), 141-150.

Davoglio, T. R., Spagnolo, C., \& Santos, B. S. (2017). Motivação para a permanência na profissão: a percepção dos docentes universitários. Revista Psicologia Escolar e Educacional, 21 (2), 175-182.

Dejours, C. (2007). A banalização da injustiça social. Rio de Janeiro: FGV.

Dejours, C. (2008). Avaliação do trabalho submetido à prova do real: crítica aos fundamentos da avaliação. In L. I. Sznelwar, \& F. L. Mascia (Orgs.), Trabalho, tecnologia e organização (vol. 2). São Paulo: Blucher.

Dejours, C. (2011). A carga psíquica do trabalho. In C. Dejours, E. Abdoucheli, \& C. Jayet (Orgs.), Psicodinâmica do trabalho: contribuições da escola dejouriana à análise da relação prazer, sofrimento e trabalho. São Paulo: Atlas.

Dejours, C. (2012). Psicodinâmica do trabalho e teoria da sedução. Psicologia em Estudo, 17(3), 363-371.

Dejours, C. (2015). A loucura do trabalho: estudo de psicopatologia do trabalho. São Paulo: Cortez.

Dejours, C. (2017). Psicodinâmica do trabalho: casos clínicos. Porto Alegre: Dublinense.

Dejours, C., Deranty, J. P., Renault, E., \& Smith, N. (2018). The return of work in critical theory: self, society, politics. New York: Columbia University Press.

Diehl, L., \& Marin, A. H. (2016). Adoecimento mental em professores brasileiros: revisão sistemática da literatura. Estudos Interdisciplinares em Psicologia, 7(2), 64-85.

Facci, M. G. D., Urt, S. C., \& Barros, A. T. F. (2018). Professor readaptado: a precarização do trabalho docente e o adoecimento. Psicologia Escolar e Educacional, 22 (2), 281-290.

Fernández, R. A., Navarro, E. M., \& Fierro, A. A. (2018). Buen o buena docente de universidad: Perspectiva del personal directivo de carrera y de los mismos grupos docentes. Revista Eletrónica Educare, 22 (2), 1-27.

Ferreira, A. C. S. P., Ferenc, A. V. F., \& Wassem, J. (2018). Trabalho docente e avaliação da Capes: estranhamento e naturalização. Educação E̊ Realidade, 43(4), 1321-1341.

Ferreira, L. L. (2019). Lições de professores em suas alegrias e dores no trabalho. Cadernos de Saúde Pública, 35 (suppl. 1), e00049018.

Forattini, C. D., \& Lucena, C. (2015). Adoecimento e sofrimento docente na perspectiva da precarização do trabalho. Laplage em Revista, 1(2), 32-47.

Gouvernet, B., Mouchard, J., \& Combaluzier, S. (2015). Analyses en pistes causales d'un modèle d'une organisation fonctionnelle des relations entre mécanismes de défense et stratégias de coping. L'Encéphale, 41(5), 403411.

Hoffmann, C., Zanini, R. R., Moura, G. L., Costa, V. M. F., \& Comoretto, E. (2017). Psicodinâmica do trabalho e riscos de adoecimento no magistério superior. Estudos Avançados, 31(91), 257-276.

Hoffmann, C., Marchi, J., Comoretto, E., \& Moura, G. L. (2018). Relações entre autoconceito profissional e produtivismo na pós-graduação. Psicologia Ė Sociedade, 30(1), 1-10.

Leite, A. F. \& Nogueira, J. A. D. (2017). Fatores condicionantes de saúde relacionados ao trabalho de professores universitários da área da saúde: uma revisão integrativa. Revista Brasileira de Saúde Ocupacional, 42 (6), 1 15.

Llapa, E. O. R., Silva, G. G., Neto, D. L., López, M. J. M., Seva, A. M. L., \& Gois, C. F. L. (2015). Uso de práticas integrativas e complementares no tratamento de estresse ocupacional: uma revisão integrativa. Enfermería Global: Revista Electrónica Trimestral de Enfermería, 39(1), 304-315. 
Loureiro, T., Mendes, G. H. S., \& Silva, E. P. (2018). Estigma, invisibilidade e intensificação do trabalho: estratégias de enfrentamento do sofrimento pelos assistentes em administração. Trabalho, Educação e Saúde, 16(2), 703-728.

Martinéz, D. (1997). El malestar docente. In D. Martinéz, I. Valles, \& J. Kohen (Orgs.), Salud y trabajo docente: tramas del malestar e la escuela (pp. 111-136). Buenos Aires: Kapelusz.

Maturana, A. P. P. M., \& Valle, T. G. M. (2014). Estratégias de enfrentamento e situações estressoras de profissionais no ambiente hospitalar. Psicologia Hospitalar, 12(1), 2-23.

Mendes, A. M. B., \& Ferreira, M. C. (2007). Inventário de Trabalho e Riscos de Adoecimento, ITRA: instrumento auxiliar de diagnóstico de indicadores críticos no trabalho. In A. M. B. Mendes (Org.), Psicodinâmica do trabalho: teoria, método e pesquisa. São Paulo: Casa do Psicólogo.

Medeiros, A. M., \& Vieira, M. T. (2019). Ausência ao trabalho por distúrbio vocal de professores da Educação Básica no Brasil. Cadernos de Saúde Pública, 35 (suppl. 1), e00171717.

Minayo, M. C. S. (2017). Amostragem e saturação em pesquisa qualitativa: consensos e controvérsias. Revista Pesquisa Qualitativa, 5(7), 01-12.

Ministério da Saúde (2012). Resolução no 466, de 12 de dezembro de 2012. Aprova diretrizes e normas regulamentadoras de pesquisas envolvendo seres humanos. Diário Oficial da União. Brasília.

Ministério da Saúde (2016). Resolução no 510, de 7 de abril de 2016. Aprova diretrizes e normas regulamentadoras de pesquisas envolvendo seres humanos. Diário Oficial da União. Brasília.

Monsalve, A. S. (2016). A identidade docente de professores de pós-graduação médica e cirúrgica em um hospital universitário: um olhar a partir das histórias de vida. Ciências da Saúde, 14(1), 75-92.

Moreira, D. A., Tibães, H. B. B., \& Brito, M. J. M. (2018). Prazer e sofrimento de docentes na pós-graduação stricto sensu em enfermagem. Revista Rene, 19(1), e33328.

Oliveira, C. A. F. B., Almeida, C. M., Souza, N. V. D. O., Pires, A. S., \& Madriaga, L. C. V. (2017). Prazer e sofrimento no trabalho: perspectivas de docentes de enfermagem. Revista Baiana de Enfermagem, 31 (3), 2029.

Oliveira, A. S. D., Pereira, M. S., \& Lima, L. M. (2017). Trabalho, produtivismo e adoecimento dos docentes nas universidades públicas brasileiras. Psicologia Escolar e Educacional, 21 (3), 609-619.

Penteado, R. Z., \& Neto, S. S. (2019). Mal-estar, sofrimento e adoecimento do professor: de narrativas do trabalho e da cultura docente à docência como profissão. Saúde e Sociedade, 28(1),135-153.

Pietrowski, D. L., Cardoso, N. O., \& Bernardi, C. C. N. (2018). Estratégias de coping frente à síndrome de burnout entre os professores: uma revisão integrativa da literatura nacional. Contextos Clínicos, 11(3), 397-409.

Ravalier, J. M., Wegrzynek, P., \& Lawton, S. (2016). Systematic review: complentary therapies and employee wellbeing. Occupational Medicine, 66(1), 428-436.

Reis, L. A., \& Menezes, T. M. O. (2017). Religiosidade e espiritualidade nas estratégias de resiliência do idoso longevo no cotidiano. Revista Brasileira de Enfermagem, 70(4), 794-799.

Ruza, F. M., \& Silva, E. P. (2016). As transformações produtivas na pós-graduação: o prazer no trabalho docente está suspenso? Revista Subjetividades, 16(1) 91-103.

Santos, S. M. M., Maia, E. G., Claro, R. M., \& Medeiros, A. M. (2019). Limitação do uso da voz na atividade física de ensino e lazer: Estudo Educatel, Brasil, 2015/2016. Cadernos de Saúde Pública, 35 (suppl. 1), e00188317.

Silva, L. C., \& Salles, T. L. A. (2016). O estresse ocupacional e as formas alternativas de tratamento. Recape: Revista de Carreiras de Pessoas, 6(2), 234-247.

Silva, Q. L., Menezes, T. F. A., \& Cassunde, F. R. S. J. (2016). Esgotamento psicológico no trabalho: uma análise sob a ótica da síndrome de burnout em professores do ensino fundamental. Line Multidisciplinary and Psychology Journal, 10(29), 37-47.

Silva, A. V., \& Piolli, E. (2017). A centralidade na psicodinâmica de Christophe Dejours, o campo educacional e o trabalho docente: aproximações possíveis. Devir Educação, 1(1), 50-65.

Silveira, K. A., Enumo, S. R. F., \& Batista, E. P. (2014). Indicadores de estresse e estratégias de enfrentamento em professores de ensino multisseriado. Psicologia Escolar e Educacional, 18(3), 457-465.

Silveira, S. S., \& Bendassolli, P. F. (2018). Estratégias de conciliação trabalho-família de professores universitários em uma capital do Nordeste brasileiro. Revista Psicologia: Organização e Trabalho, 18(3), 422-429. 
Souto, B. L. C., Beck, C. L. C., Trindade, L. R., Silva, R. M., Backes, D. S., \& Bastos, R. A. (2017). O trabalho docente em pós-graduação: prazer e sofrimento. Revista de Enfermagem da UFSM, 7(1), 29-39. http:// dx.doi.org/10.5902/2179769222871

Tundis, A. G. O., Monteiro, J. K., Santos, A. S., \& Dalenogare, F. S. (2018). Estratégias de mediação no trabalho docente: um estudo em uma universidade pública na amazônia. Educação, 34(1), 1-23.

Tundis, A. G. O., \& Monteiro, J. K. (2018). Ensino superior e adoecimento docente: um estudo em uma universidade pública. Psicologia da Educação, 46(1), 1-10.

Valadão, M. B., \& Neto, S. B. C. (2019). Estresse ocupacional e estratégias de enfrentamento psicológico de docentes do ensino superior de Goiânia. In I. G. S. Arioli (Org.), Psicologia da saúde: teoria e intervenção. Ponta Grossa, PR: Atena.

Vieira, F. O., Mendes, A. M., \& Merlo, A. R. C. (2013). Dicionário crítico de gestão e psicodinâmica do trabalho. Curitiba: Juruá.

Vilela, E. F., Garcia, F. C., \& Vieira, A. (2013). Vivências de prazer-sofrimento no trabalho do professor universitário: estudo de caso em uma instituição pública. Revista eletrônica de administração, 75 (2), 517-540.

\section{Endereço para correspondência}

chancarlyne@unochapeco.edu.br, letrindade@hotmail.com, rrezer@unochapeco.edu.br, carine.vendruscolo@udesc.br, rodriguesjunior.sa@unochapeco.edu.br 